\title{
Evaluation of the Reflux Symptom Index and the Endolaryngeal Findings Scale after Treatment in Individuals with Laryngopharyngeal Reflux
}

\author{
Álvaro Siqueira Silva ${ }^{10}$ André Campos Duprat ${ }^{20}$ \\ Dayse Kelle Nascimento Ribeiro ${ }^{3}$ \\ ${ }^{1}$ Amazonas State University, Manaus, AM, Brazil \\ 2 Otorhinolaryngology Department, Medical Sciences College, Santa \\ Casa de São Paulo, São Paulo, SP, Brazil \\ 3 Otorhinolaryngology and Cervical-facial Surgery at the Adriano \\ Jorge Hospital Foundation, Manaus, AM, Brazil
}

\author{
Súnia Ribeiro Machado ${ }^{1}$ Daniele Nahmias Melo ${ }^{1}{ }^{10}$
}

Int Arch Otorhinolaryngol 2021;25(1):e115-e122.

\begin{abstract}
Address for correspondence Álvaro Siqueira Silva, PhD, Amazonas State University, Av. Castelo Branco, 1403-A, Cachoeirinha, Manaus, AM, 69065-001, Brazil (e-mail: alvarosiq@uol.com.br).
\end{abstract}

\begin{abstract}
Keywords

- laryngopharyngeal reflux

- proton pump inhibitors

- treatment outcome

Introduction Laryngopharyngeal reflux (LPR) is a prevalent condition in outpatients visiting the otorhinolaryngological clinic, with many controversies regarding its diagnosis and follow-up. Therefore, there is a need for clinical instruments that can diagnose individuals and monitor the results of their treatment.

Objective To evaluate the applicability of the scores translated and adapted to Brazilian Portuguese: Reflux Symptom Index (RSI) and Endolaryngeal Reflux Findings Scale (ERFS), as instruments for post-treatment follow-up of LPR.

Method A total of 35 individuals with atypical symptoms of gastroesophageal reflux disease and with an objective diagnosis of LPR, confirmed by high digestive endoscopy and 24-hour esophageal pH-metry dual probe test were submitted to the RSI and ERFS questionnaires, used in the pre- and post-treatment of 90 days with a Proton Pump Inhibitor. Result The evaluation of RSI and ERFS in the pre- and post-treatment showed a reduction in the results of the two scores, with a higher drop in the RSI $(p<0.001)$ than in the ERFS $(p=0.014)$. Although there was an improvement in the values in $23.9 \%$ of the individuals in the ERFS, there was no change in the category $(p=0.057)$, different from the RSI $(p<0.001)$, where there was a $67.4 \%$ improvement in values, as well as change in category (score went from positive to negative). There was a correlation between RSI and ERFS, moderate in the pretreatment and strong in the post-treatment.

Conclusion The RSI and ERFS scores, when translated and adapted for Brazilian Portuguese and applied simultaneously, can be considered a good tool for posttreatment LPR follow-up.
\end{abstract}

received

June 28, 2019

accepted

December 15, 2019

published online

May 4, 2020
DOI https://doi.org/

10.1055/s-0040-1702967. ISSN 1809-9777. (c) 2020. Fundação Otorrinolaringologia. All rights reserved.

This is an open access article published by Thieme under the terms of the Creative Commons Attribution-NonDerivative-NonCommercial-License, permitting copying and reproduction so long as the original work is given appropriate credit. Contents may not be used for commercial purposes, or adapted, remixed, transformed or built upon. (https://creativecommons.org/ licenses/by-nc-nd/4.0/)

Thieme Revinter Publicações Ltda., Rua do Matoso 170, Rio de Janeiro, RJ, CEP 20270-135, Brazil 


\section{Introduction}

Laryngopharyngeal reflux (LPR), considered an extra-esophageal manifestation of gastroesophageal reflux disease (GERD), consists of the retrograde flow of gastric contents into the esophagus, larynx and pharynx, causing tissue damage in these regions, as well as symptoms such as odynophagia, pharyngeal globus, throat clearing, dysphonia, dry cough and laryngospasm crisis. ${ }^{1-4}$

Despite advances in the knowledge regarding the pathophysiology and therapeutics of LPR, there are still many controversies regarding its diagnosis and follow-up. ${ }^{5-7}$

Because they present distinct clinical manifestations, diagnostic tests for the gastro-esophageal region do not always apply to LPR, since these tests depend on subjective signs and symptoms in the laryngopharyngeal follow-up. ${ }^{7-9}$

The questionnaires applied in the diagnosis of GERD were developed according to the severity of signs and symptoms and the response to treatment with proton pump inhibitors (PPIs). However, they do not consider the findings encountered in LPR, and are not, therefore, a valid instrument for otorhinolaryngologists. ${ }^{2}$

Prado et al, in 2013, after translation into Brazilian Portuguese and cultural adaptations, tested the reliability of the Reflux Finding Score (RFS), which evaluates laryngeal inflammatory signs through video laryngoscopic findings, and thus decreases the subjectivity of the diagnosis. This translated score was renamed Endolaryngeal Reflux Scale (ERFS), and evaluated the following sub-domains: subglottic edema, ventricular obliteration, erythema and hyperemia of the larynx, vocal fold edema, diffuse laryngeal edema, hyperarousal of the interarytenoid region, granuloma and thick endolaryngeal mucus. ${ }^{10}$

In 2015, Saliture translated into Brazilian Portuguese and made the cultural adaptation of the Reflux Symptons Index (RSI), to be called "Índice de Sintomas de Refluxo" (ISR).The symptoms are: voice problems, throat clearing, excessive throat secretion, difficulty in swallowing food or liquids, coughing after eating or lying down, suffocation crises, irritating cough, sensation of having a ball in the throat, burning, pain in the chest, or acid sensation in the stomach rising to the throat. ${ }^{11}$

Subsequent research was conducted to test the sensitivity, applicability and reproducibility of RSI and RFS in other languages, investigating the relationship between the presence and intensity of LPR with endolaryngeal symptoms and changes found in the examination. The results showed a relationship between the symptoms and the laryngeal alterations when LPR is present. ${ }^{12-14}$

Due to the controversies and difficulties in evaluating the signs and symptoms of LPR, it is necessary to evaluate the applicability of the ERFS and RSI scores translated and adapted to Brazilian Portuguese to discover their utility as instruments for post-treatment follow-up of LPR.

\section{Methods}

\section{Casuistry}

The present project was approved by the Research Ethics Committee under protocol no. 021/10.
A total of 70 individuals with atypical symptoms of GERD (throat clearing, dysphonia, pharyngeal globus, chronic cough), without distinction of gender, aged $\geq 18$ years old, were selected consecutively from otorhinolaryngology outpatient clinics.

The translated and adapted questionnaires were applied based on symptoms (RSI) and on the endolaryngeal reflux findings scale (ERFS), and the patients were submitted to upper digestive endoscopy (HDE). Subsequently, they were submitted to a 24-hour esophageal $\mathrm{pH}$-metry dual probe test. The selected patients agreed to participate in the study by signing the Term of Free and Informed Consent (TC), with information about the objectives, procedures used and risks involved.

The exclusion criteria were: individuals with psychiatric illness, pregnant women, individuals using gastric secretion blocking drugs, pro-kinetics or antacids in the seven days prior to the examination or hormonal (oral and inhaled) and non-hormonal anti-inflammatory drugs in the period preceding the present study ( 2 weeks), presence of smoking, alcoholism, history of exposure to abrasive inhalation chemicals, lung diseases, allergic or infectious rhinosinusitis and other active conditions of the airways; these were discarded through clinical examination, previous history of surgery of the digestive system and presence of anatomical alterations, pre-neoplastic, granulomatous or neoplastic lesions of the pharynx and larynx (present or previously treated). Such factors may mimic the laryngeal changes and symptoms resulting from GERD/LPR. ${ }^{3}$

Individuals who did not tolerate rigid video laryngoscopy, those who refused to perform the diagnostic tests, as well as those with intolerance to PPI (omeprazole $80 \mathrm{mg} /$ day) and/or dropout in the period established for the present study (90 days) were also excluded from the present study.

\section{Procedure}

Individuals with extra esophageal manifestations of GERD answered the questionnaire on general otolaryngological symptoms, digestive symptoms and the Reflux Symptom Index (RSI). Regardless of the score, all of the subjects underwent video laryngoscopy with a $10 \mathrm{~mm}$ and $70^{\circ}$ rigid laryngoscope (Model 8700 CKA, Karl Storz GmbH \& Co, Tuttlingen, BadenWürttemberg, Germany) coupled to the video system (Model: IK-CU44A, Toshiba - Ōtawara, Tochigi, Japan) and Monitor (Modelo 20m35pd-m, LG ELECTRONICS, Manaus, Amazonas, Brazil). All of the exams were stored on digital video disc(DVD) media. The scanned images received an $\alpha$ numeric code and were randomly mixed for analysis using the ERFS.

The individuals were then submitted to HDE with biopsy. The presence and severity of esophagitis were evaluated by the Los Angeles Classification.

Esophageal manometry was performed before $\mathrm{pH}$ metry to determine tone and position of the upper esophageal sphincter (UES), the lower esophageal sphincter (LES), and esophageal body motility. These data were used for the placement of the pH-metry dual antimony probe, being the distal sensor positioned $5 \mathrm{~cm}$ from the LES and the proximal one $20 \mathrm{~cm}$ from the LES, that is, in 


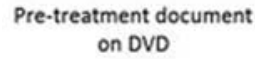
on DVD

Fig. 1 Flowchart used in the study to investigate and diagnose laryngopharyngeal reflux.

the proximal esophagus. De Meester parameters were considered positive for LPR for the distal sensor and for the proximal sensor the presence of $\geq 1$ episodes with $\mathrm{pH}<4$. Also diagnosed with Laryngopharyngeal reflux (LPR) were individuals with proximal and distal (double) positive $\mathrm{pH}$-metries, and we excluded those with positive results for the distal sensor only.

After the objective diagnosis of LPR was established through HDE and 24-hour esophageal pH-metry dual probe test, the subjects were treated with oral PPI (omeprazole), $80 \mathrm{mg} /$ day, divided into two daily doses (morning on an empty stomach, and before dinner) for 90 days and advised on the correction of lifestyle and eating habits.

The individuals were reevaluated after 90 days of PPI treatment whereupon the RSI and ERFS were repeated, according to the flowchart (-Fig. 1).

We considered the numerical values, tabulated in the Microsoft Excel (Microsoft Corporation, Redmond, WA, USA) program, assigned to the total sum of the RSI and ERFS, as well as the scores given to the sub-domains of the scores used in the pre- and post-treatment. We also evaluated the correlation of responses of the individuals to the RSI and to the ERFS, as well as the correlation of symptoms suggestive of reflux and endolaryngeal signs.

\section{Statistical Analysis}

The data were statistically analyzed using SPSS Statistics, version 13.0 for Windows software (SPSS Inc., Chicago, IL, USA), and the McNemar and t-paired tests were applied. A value of $p<0.05$ was considered significant.
The Pearson correlation was used to compare the total scores and the sub-domains of ERFS and RSI, and a $p$-value $<0.05$ was considered significant.

\section{Results}

Out of the 70 individuals selected due to suspected LPR, 35 were excluded: 8 because they could not perform HDE, 7 because they had normal results for the 24-hour esophageal pH-metry dual probe test, 4 because they were positive only at the distal sensor, 2 because they had $\mathrm{pH}>4$ on the proximal sensor, 7 for not performing esophageal pH-metry dual probe test and 7 left the study over the 90-day period.

Thus, the study sample consisted of 35 individuals with an objective diagnosis of LPR, confirmed by HDE and pH-metry, who were submitted to the RSI and ERFS questionnaires, before and after treatment with PPI. Of these 35 individuals, 30 (85.7\%) were female and 5 (14.3\%) were male. Age ranged from 29 to 73 years old, with a mean of 47.2 years old.

A total of 35 patients needed to perform 24-hour esophageal $\mathrm{pH}$-metry dual probe test for diagnostic confirmation of LPR. The results showed 29 individuals (82.8\%) with results compatible with proximal pathological reflux $(\mathrm{pH}<4)$.

The RSI assessment, through the sum total of the subdomains, showed a reduction in the values when compared with the pre- and post-treatment, $16.3( \pm 2.5)$ being the mean in the pretreatment, with a mean of 16.0; in the post-treatment, the value was $10.9( \pm 4.0)$ with a mean of 10.5. A statistically significant difference was observed $(p<0.001)$. 


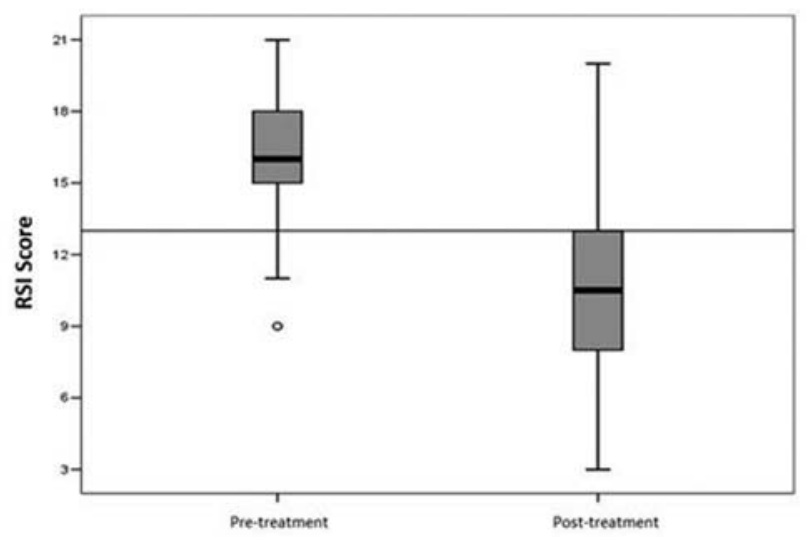

Fig. 2 Graph of total RSI values before and after 90 days of proton pump inhibitor treatment.

In - Fig. 2, we can observe that after treatment for 90 days with PPI, most were below the black line representing the positivity for the altered score (RSI $>13$ ).

The symptoms of RSI sub-domains that improved after PPI treatment were: sensation of a ball in the throat in 24 individuals (68.6\%), followed by throat clearing in 16 individuals (45.7\%), (-Fig. 3 ).

In the ERFS evaluation, the total sum of the sub-domains showed a reduction in values, $10.8( \pm 3.9)$ was the mean in pre-treatment, and in the post-treatment the mean was of $9.4( \pm 3.8)$, with a median of 9.0. A statistically significant difference was observed ( $p=0.014)$. The means of the preand post-treatments were 10.5 and 9.0, respectively.

In - Fig. 4, we can observe that after treatment for 90 days with PPI, even with reduction of values, most were above the

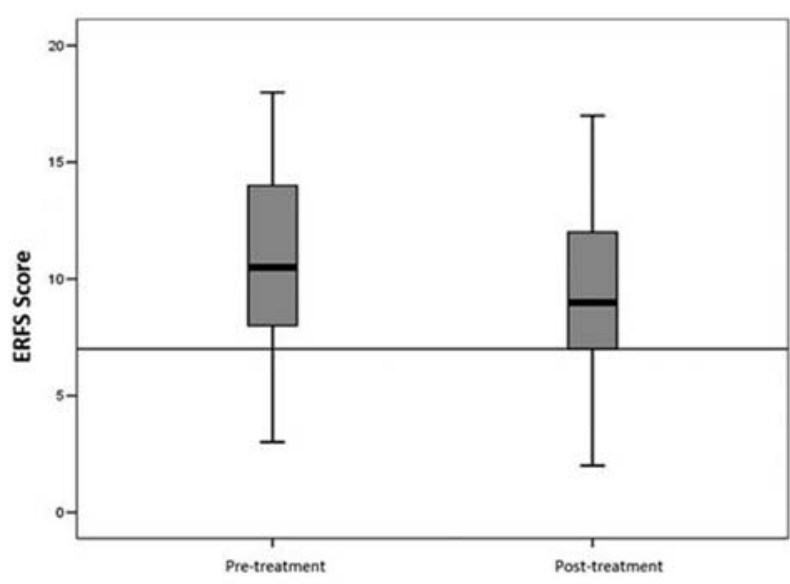

Fig. 4 Graph of total ERFS values before and after 90 days of proton pump inhibitor treatment.

line that represents a positive result for the altered score (ERFS $>7$ ).

Of the sub-domains of ERFS, the only endolaryngeal sign that improved in total was erythema/hyperemia (43.5\%).

There was a reduction in the total ERFS value when comparing pre- and post-treatment for 90 days of PPI, but we observed that most of the laryngoscopic signs were maintained, even during treatment (-Fig. 5).

The evaluation of the relationship between the total and sub-domains of ERFS and RSI in the pre- and post-treatment, through the Pearson correlation with a representative value of $p<0.01$, showed a moderate correlation $(r=0.599)$ in pre-treatment and a strong correlation $(\mathrm{r}=0.868)$ after treatment (-Fig. 6, - Fig. 7).

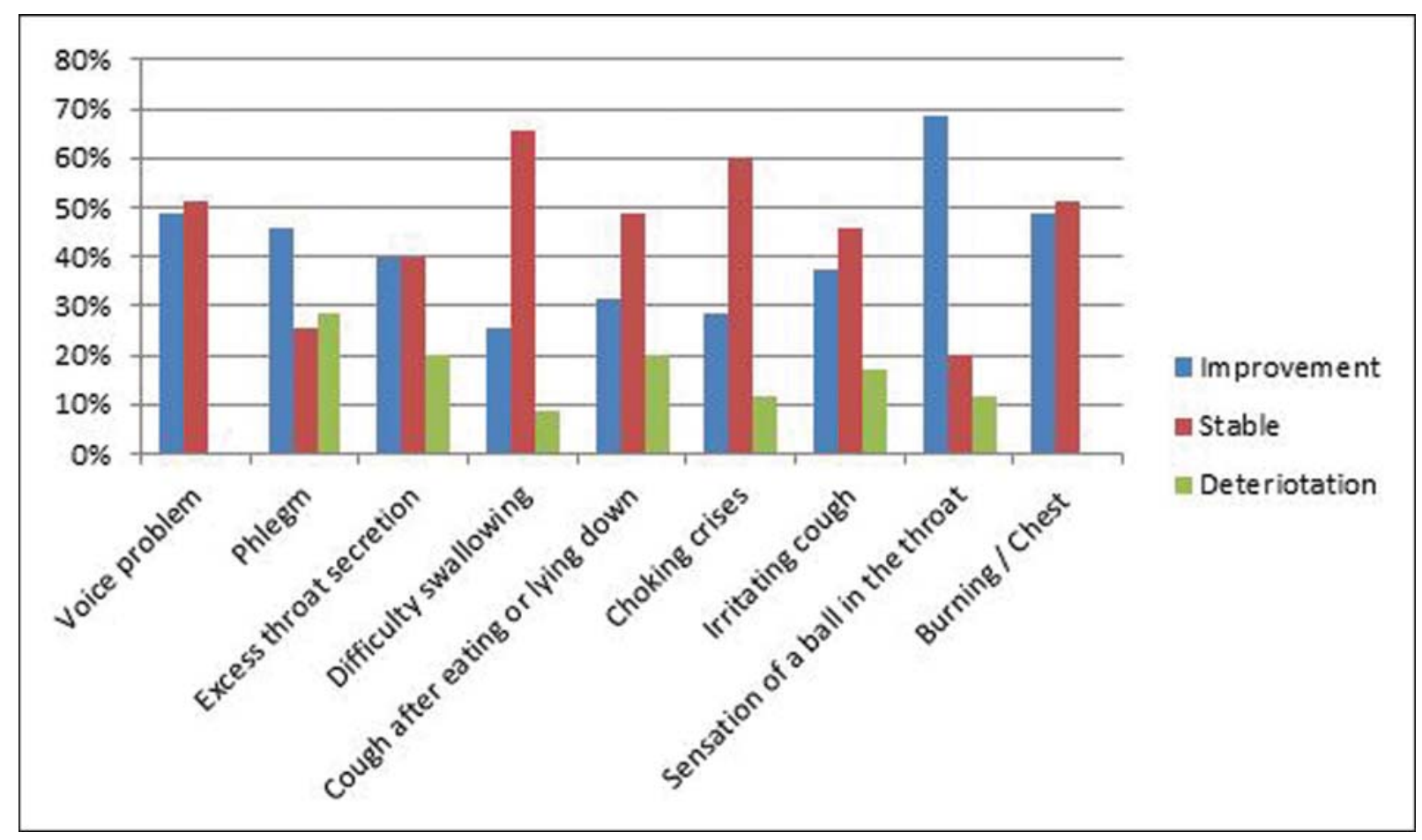

Fig. 3 Evaluation Graph for the RSI pre-and post-treatment sub-domains for 90 days with proton pump inhibitor. 


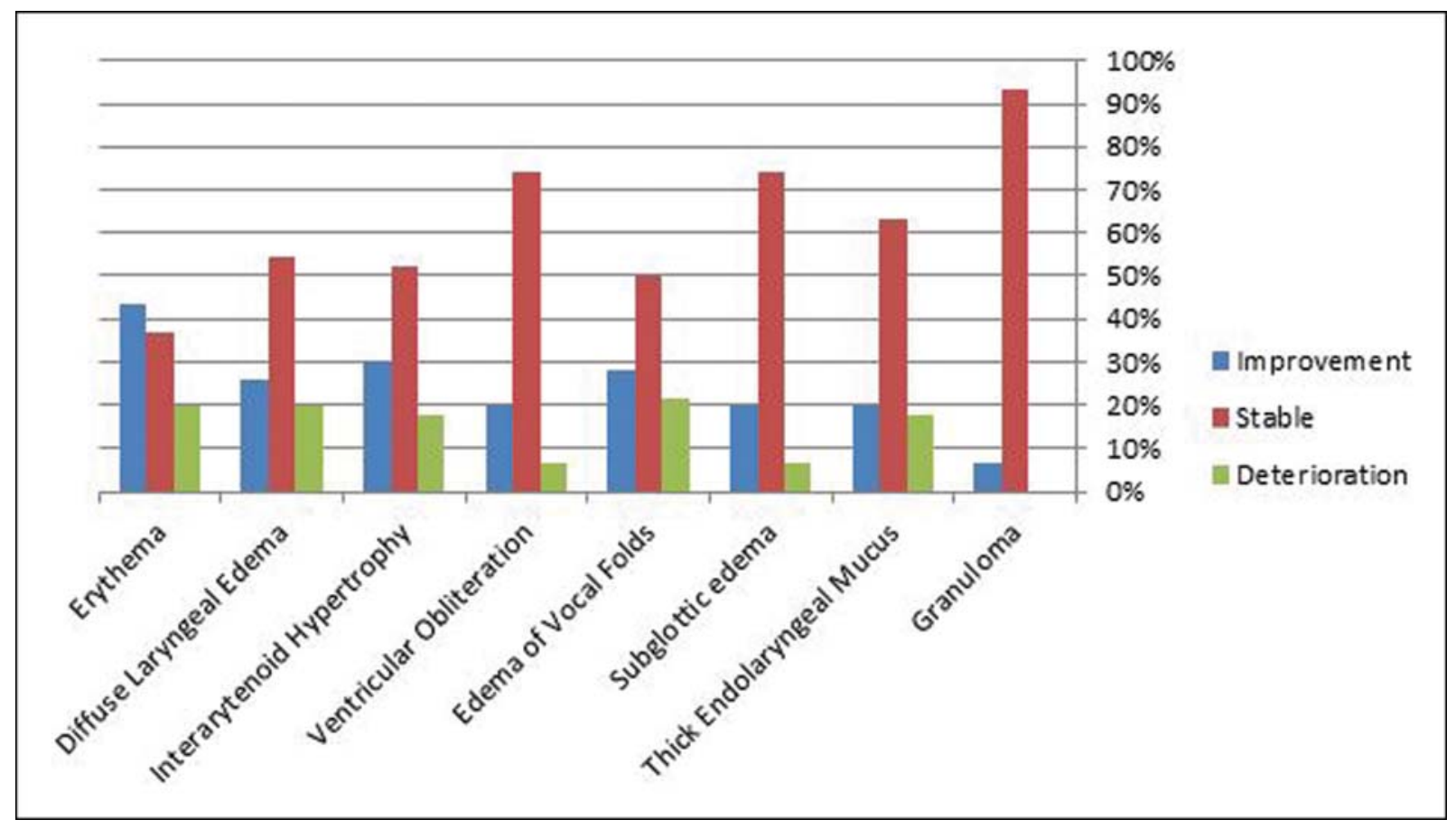

Fig. 5 Evaluation chart of the pre-and post-treatment ERFS sub-domains for 90 days with proton pump inhibitor.

\section{Discussion}

Despite the advances in the knowledge of the atypical manifestations of GERD, the clinical diagnosis of LPR is still controversial, mainly due to the possibility that laryngeal and pharyngeal inflammatory signs suggestive of reflux may be common to other exogenous irritative diseases or processes, so this study applied strict exclusion criteria. Smoking and alcoholism, for example, cause an inflammatory process in the respiratory mucosa, and may mimic other possible causes of chronic laryngitis, such as those found in endolaryngeal changes in LPR. ${ }^{3,15,16}$

Symptoms associated with LPR are prevalent in outpatients who visit the ENT office. Therefore, there is a need for clinical instruments that can diagnose individuals and mon-

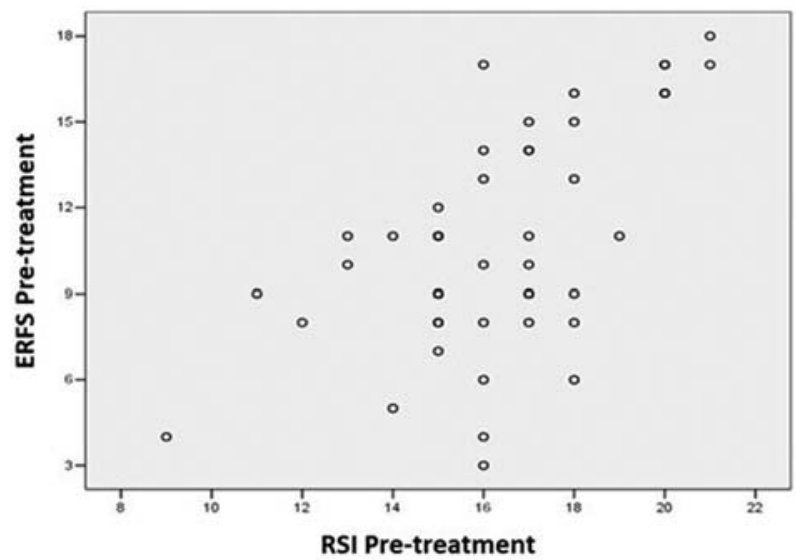

Fig. 6 Graph of the correlation of ERFS and RSI in proton pump inhibitor pre-treatment during 90 days. itor treatment outcomes. Belafsky et al had already proposed the Reflux Finding Score (RFS) and the Reflux Symptoms Index (RSI) questionnaires as diagnostic and prognostic tools for LPR. 8,17

Despite the reproducibility found in these scores, we noticed the obstacles to their application due to the difficulty of understanding the original language for other languages. Thus, the need for translation and cultural adaptation to different languages. ${ }^{12-14}$ The present study was the first to use the ERFS and the RSI, questionnaires translated and adapted to the Brazilian Portuguese language.

According to Moraes-Filho, the empirical treatment for LPR without standardization of diagnostic criteria is insufficient, and, as such, empirical treatment is an unsatisfactory

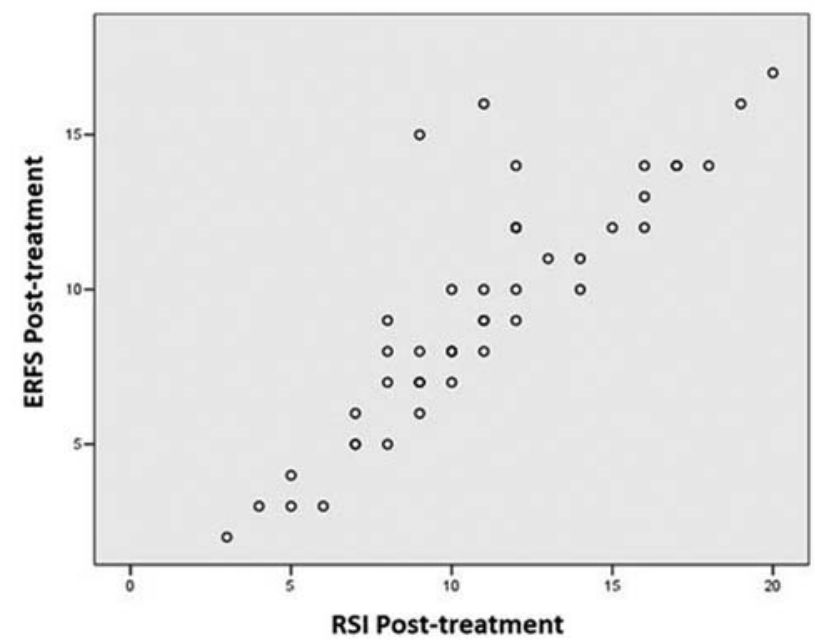

Fig. 7 Graph of the correlation of ERFS and RSI in proton pump inhibitor post-treatment during 90 days. 
form of conduct. On the other hand, Iglesia et al advocate the initiation of empirical treatment for LPR based on subjective diagnostic criteria via RSI and RFS. ${ }^{2,18}$

Regarding the demographic findings, the female gender prevailed (82.6\%) and the mean age was 47.2 years old, data that are consistent with those found in the literature. ${ }^{19}$

It was observed in the present study that the majority of the individuals with atypical symptoms of GERD, under HDE, showed gastritis without esophagitis (73\%) and only $15.2 \%$ with erosive esophagitis according to the Los Angeles criteria. These findings were compatible with the literature, which describes the presence of erosive esophagitis in 10 to $20 \%$ of individuals with LPR. ${ }^{20,21}$

Despite being an option for diagnosis of LPR, HDE has low sensitivity and is considered a poor tool when used on its own to diagnose $\mathrm{LPR}^{20-22}$

In the present study, a change in the 24-hour esophageal pH-metry dual probe test results was found in 29 individuals $(82.8 \%)$, and the cut-off value for the diagnosis of proximal reflux was the presence of any episode of $\mathrm{pH}<4$. This prevalence was in accordance with the findings of Marambaia et al, who observed alterations in pH-metry in $83.6 \%$ of individuals with LPR. ${ }^{23}$

The diagnostic sensitivity of the prolonged esophageal monitoring exams by 24-hour esophageal pH-metry dual probe test is known to be low, varying from 40 to $80 \%$. In the current study, we found alterations in $84.7 \%$ of the 35 subjects submitted to pH-metry. However, in the review of the literature performed by Joniau et al, they concluded that, even when using the 24-hour esophageal pH-metry dual probe test, there was no statistical significance when comparing the group with LPR and the control group. ${ }^{24,25}$

Waxman et al evaluated individuals with LPR by means of RSI associated with pH-metry in the pre- and post-treatment, and the participants received PPI for 4 weeks. They observed improvement of the RSI in $67.4 \%$ of the patients. On the other hand, in pH-metry there was no improvement in $60.5 \%$ of the patients. Even so, they concluded that there is a need for $\mathrm{pH}$-metry in the pre- and post-therapy to verify the duration and efficacy of PPI treatment. ${ }^{26}$

In our study, post-treatment pH-metry was not used because of the difficulties of availability in the public network and also because of low acceptance by the patients, so the ERFS and RSI scores were considered as follow-up instruments after gold standard treatment with double daily doses of PPI. There was an improvement in the symptoms and signs suggestive of LPR without having to submit the patients to a more invasive examination.

When we considered the RSI score as an indicator of post-treatment LPR follow-up, it was noticed that there was a reduction in the total pre- and post-treatment values with statistical significance $(p<0.001)$, from 16.3 to 10.9 . The reduction was on average 5.4 points in 90 days, proving it to be a good tool for LPR follow-up. Saliture observed in his results that when the cutoff point of the total RSI score was lowered to nine, the sensitivity of the test did not decrease. The same result was found by Printza et al in their validation of this score for the Greek language version. In their study, however, Park et al concluded that the RSI has no diagnostic value when used on its own because of the presence of non-LPR-related psychological symptoms. ${ }^{11,13,27}$

In our study, when sub-domains were analyzed separately from the RSI, improvement was only noticed in two items: sensation of a ball in the throat (68.6\%) and throat clearing (45.7\%), findings which are compatible with those in the literature. $^{19,28}$

In the evaluation of RSI and ERFS in the pre- and post90-day treatment with PPI, a reduction in the scores was observed in both scores, with a higher drop in the RSI $(p<0.001)$ than in the ERFS $(p=0.014)$. Even though there was a reduction of values in $23.9 \%$ of the individuals, there was no change in the category of ERFS ( $p=0.057)$. Differently from the RSI $(p<0.001)$, in which, besides an improvement in $67.4 \%$ of the patients, a change of category was observed (the score changed from positive to negative).

Regarding the results of the ERFS, differently from the other studies, we observed a reduction of the total value when comparing pre- and post-treatment with 90 days of PPI, from 10.8 to 9.4 , with statistical significance $(p<0.014)$.

When we analyzed the sub-domains of the ERFS after 90 days of PPI treatment, there was improvement of only one sub-domain, erythema/hyperemia in $43.5 \%$, while others (subglottic edema, ventricular obliteration, vocal fold edema, hypertrophy of the interarytenoid region, granuloma and mucus) remained unchanged, causing the ERFS to remain greater than seven.

Reichel et al observed improvement of post-treatment posterior commissure hypertrophy. In contrast, Hill et al concluded that posterior commissure hypertrophy on its own is not a reliable finding for LPR diagnosis. Our study agreed with the improvement of the sub-domain erythema/hyperemia, also found by Lee et al, who also observed improvement in vocal fold edema and diffuse edema of the larynx, the rest of the sub-domains remained unchanged in the posttreatment. $^{15,19,28}$

This finding leads us to question the duration of treatment, which in the present study led to a discrete reduction in the overall sum of the ERFS from 10.8 to 9.4. Perhaps a longer follow-up time could change the profile of this score, since our follow-up was of only 90 days.

Despite the slight improvement in the ERFS after 90 days of PPI treatment, using the traditional cutoff point of seven as positive for LPR, this finding allowed us to recognize that LPR laryngoscopy was reliable. We therefore consider the ERFS as a good tool for post-treatment LPR follow-up, in agreement with the findings of Park et al. ${ }^{17,27}$

When we analyzed the correlation of the ERFS and the RSI as instruments for post-treatment follow-up of LPR, we noticed a moderate correlation in pre-treatment $(r=0.599)$ and a strong correlation in the post-treatment with PPI $(\mathrm{r}=0.868)$, and these results are compatible with those of Church et al. These findings are suggestive that individuals who improved their symptoms also had improvement of endolaryngeal findings. ${ }^{18}$ 
The significant difference in RSI and ERFS scores in the pre- and post-treatment of individuals with LPR also validates these instruments as prognostic tools. Despite the significant improvement, the values of RSI $>13$ and ERFS $>7$ in the post-treatment may imply the need for a longer treatment for these individuals. This finding was confirmed by Belafsky et al, who found a significant improvement in the score of individuals treated with PPIs for a period of 6 months, double the time used in our study. 8,17

We can highlight as limitation of the present study the exclusive selection of patients with acid LPR, not including patients with non-acid reflux. Individuals with normal double-channel $\mathrm{pH}$ monitoring may eventually have non-acidic LPR, which could be observed by performing $\mathrm{pH}$-impedance, not used in the present study. ${ }^{29}$

Another limitation found refers to the RSI. First, by not considering the frequency of symptoms, focusing only on their severity; and second because it does not include many ENT-associated symptoms such as sore throat, odynophagia, halitosis and regurgitation. Similarly, many digestive complaints associated with LPR are absent, although they predominate in LPR. ${ }^{30-32}$

Lechien et al also identified RFS weakness in identifying clinical findings associated with LPR. This scale does not consider extra-laryngeal signs such as pharyngeal sticky mucus, pharyngeal wall erythema, and tongue tonsil hypertrophy, although many studies that reported that these signs may be associated with LPR. ${ }^{33-35}$

Finally, we classified the RSI and the ERFS as reliable instruments for the post-treatment follow-up of individuals with LPR, with an emphasis on the RSI, which demonstrated better results.

\section{Conclusion}

The ERFS and the RSI scores, when translated and adapted to Brazilian Portuguese and applied simultaneously, can be considered good tools for the post-treatment follow-up of laryngopharyngeal reflux.

Note

Paper presented at: $48^{\text {th }}$ ABORL-CCF Congress; October $31^{\text {st }}$ to November $3^{\text {rd }}, 2018$, João Pessoa, state of Paraíba, Brazil.

\section{Conflict of Interests}

The Authors Have No Conflict Of Interests To Declare.

\section{References}

1 Koufman JA. Reintroducing otolaryngologists to esophageal disease. Ear Nose Throat J 2001;80(07):428

2 Moraes-Filho J, Cecconello I, Gama-Rodrigues J, et al; Brazilian Consensus Group. Brazilian consensus on gastroesophageal reflux disease: proposals for assessment, classification, and management. Am J Gastroenterol 2002;97(02):241-248

3 Eckley CA, Costa HO. Salivary pH and Volume before and after treatment of LPR. Otolaryngol Head Neck Surg 2006;135:196

4 Groome M, Cotton JP, Borland M, McLeod S, Johnston DA, Dillon JF. Prevalence of laryngopharyngeal reflux in a population with gastroesophageal reflux. Laryngoscope 2007;117(08): 1424-1428

5 Ali Mel-S. Laryngopharyngeal reflux: diagnosis and treatment of a controversial disease. Curr Opin Allergy Clin Immunol 2008;8 (01):28-33

6 Gupta R, Sataloff RT. Laryngopharyngeal reflux: current concepts and questions. Curr Opin Otolaryngol Head Neck Surg 2009;17 (03):143-148

7 Hammer HF. Reflux-associated laryngitis and laryngopharyngeal reflux: a gastroenterologist's point of view. Dig Dis 2009;27(01): 14-17

8 Belafsky PC, Postma GN, Koufman JA. Validity and reliability of the reflux symptom index (RSI). J Voice 2002;16(02):274-277

9 Belafsky PC, Rees CJ. Laryngopharyngeal reflux: the value of otolaryngology examination. Curr Gastroenterol Rep 2008;10 (03):278-282

10 Prado AA, Saliture TB, Silva AS, Eckley CA. Tradução para o português brasileiro e adaptação cultural do reflux finding score. Braz J Otorhilaryngol 2013;79:47-53

12 Saliture TB. Tradução e adaptação cultural do reflux symptoms index para o português brasileiro e avaliação de suas propriedades psicométricas [dissertation]. São Paulo: Faculdade de Ciências Médicas da Santa Casa de São Paulo;2015: 97

12 Schindler A, Mozzanica F, Ginocchio D, Peri A, Bottero A, Ottaviani F. Reliability and clinical validity of the Italian Reflux Symptom Index. J Voice 2010;24(03):354-358

13 Printza A, Kyrgidis A, Oikonomidou E, Triaridis S. Assessing laryngopharyngeal reflux symptoms with the Reflux Symptom Index: validation and prevalence in the Greek population. Otolaryngol Head Neck Surg 2011;145(06):974-980

14 Farahat M, Malki KH, Mesallam TA. Development of the Arabic version of Reflux Symptom Index. J Voice 2012;26(06):814. e15-814.e19

15 Hill RK, Simpson CB, Velazquez R, Larson N. Pachydermia is not diagnostic of active laryngopharyngeal reflux disease. Laryngoscope 2004;114(09):1557-1561

16 Habermann W, Schmid C, Neumann K, Devaney T, Hammer HF. Reflux symptom index and reflux finding score in otolaryngologic practice. J Voice 2012;26(03):e123-e127

17 Belafsky PC, Postma GN, Koufman JA. The validity and reliability of the reflux finding score (RFS). Laryngoscope 2001;111(08): 1313-1317

18 Iglesia FV, Gonzáles SF, Gomez MC. Reflujo faringolaríngeo: correlación entre los síntomas y los signos mediante cuestionarios de valoración clínica y fibroendoscópica: Es suficiente para realizar el diagnostic. Acta Otorrinolaringol Esp 2007;58:421-425

19 Lee YS, Choi SH, Son YI, Park YH, Kim SY, Nam SY. Prospective, observational study using rabeprazole in 455 patients with laryngopharyngeal reflux disease. Eur Arch Otorhinolaryngol 2011;268(06):863-869

20 Lundell LRJ, Dent J, Bennett JR, et al. Endoscopic assessment of oesophagitis: clinical and functional correlates and further validation of the Los Angeles classification. Gut 1999;45(02):172-180

21 Toros SZ, Toros AB, Yüksel OD, Ozel L, Akkaynak C, Naiboglu B. Association of laryngopharyngeal manifestations and gastroesophageal reflux. Eur Arch Otorhinolaryngol 2009;266(03):403-409

22 Mahieu HF, Smit CF. Diagnosis and management of laryngopharyngeal reflux disease. Curr Opin Otolaryngol Head Neck Surg 2006;14(03):133-137

23 Marambaia O, Andrade NA, Varela DG, Juncal MC. Refluxo laringofaringeano: estudo prospectivo correlacionando achados laringoscópicos precoces com a phmanometria de 24 horas de 2 canais. Braz J Otorhilaryngol 2002;68:527-531

24 de Bortoli N, Nacci A, Savarino E, et al. How many cases of laryngopharyngeal reflux suspected by laryngoscopy are gastroesophageal reflux disease-related? World J Gastroenterol 2012; 18(32):4363-4370 
25 Joniau S, Bradshaw A, Esterman A, Carney AS. Reflux and laryngitis: a systematic review. Otolaryngol Head Neck Surg 2007;136 (05):686-692

26 Waxman J, Yalamanchali S, Valle ES, Pott T, Friedman M. Effects of proton pump inhitor therapy for laryngopharyngeal reflux on posttreatment symptons and hypopharyngeal $\mathrm{pH}$. Otolaryngol Head Neck Surg 2014;150(06):1010-1017

27 Park KH, Choi SM, Kwon SU, Yoon SW, Kim SU. Diagnosis of laryngopharyngeal reflux among globus patients. Otolaryngol Head Neck Surg 2006;134(01):81-85

28 Reichel O, Dressel H, Wiederänders K, Issing WJ. Double-blind, placebo-controlled trial with esomeprazole for symptoms and signs associated with laryngopharyngeal reflux. Otolaryngol Head Neck Surg 2008;139(03):414-420

29 Lee JS, Jung AR, Park JM, Park MJ, Lee YC, Eun YG. Comparison of Characteristics According to Reflux Type in Patients With Laryngopharyngeal Reflux. Clin Exp Otorhinolaryngol 2018;11(02): $141-145$
30 Francis DO, Patel DA, Sharda R, et al. Patient-Reported Outcome Measures Related to Laryngopharyngeal Reflux: A Systematic Review of Instrument Development and Validation. Otolaryngol Head Neck Surg 2016;155(06):923-935

31 Lechien JR, Bobin F, Muls V, et al. Validity and reliability of the reflux symptom score. Laryngoscope 2019;00:1-10

32 Chang BA, MacNeil SD, Morrison MD, Lee PK. The Reliability of the Reflux Finding Score Among General Otolaryngologists. J Voice 2015;29(05):572-577

33 Lechien JR, Schindler A, De Marrez LG, et al. Instruments evaluating the clinical findings of laryngopharyngeal reflux: A systematic review. Laryngoscope 2019;129(03):720-736

34 DelGaudio JM, Naseri I, Wise JC. Proximal pharyngeal reflux correlates with increasing severity of lingual tonsil hypertrophy. Otolaryngol Head Neck Surg 2008;138(04):473-478

35 Beaver ME, Stasney CR, Weitzel E, et al. Diagnosis of laryngopharyngeal reflux disease with digital imaging. Otolaryngol Head Neck Surg 2003;128(01):103-108 